Author affiliations appear at the end of this article.

Published online ahead of print at www.jco.org on June 6, 2016

Supported by F. Hoffmann-La Roche, Basel, Switzerland.

Terms in blue are defined in the glossary, found at the end of this article and online at www.jco.org.

Presented in part at the 51 st Annual Meeting of the American Society of Clinical Oncology, Chicago, IL, May 29-June 2, 2015.

Authors' disclosures of potential conflicts of interest are found in the article online at www.jco.org. Author contributions are found at the end of this article.

Corresponding author: Christian Kurzeder, MD, Kliniken Essen Mitte, Essen, Evang. Huyssens-Stiftung/Knappschaft $\mathrm{GmbH}$ Henricistr 92, 45136 Essen, Germany; e-mail: christian.kurzeder@yahoo.com.

(C) 2016 by American Society of Clinical Oncology

0732-183X/16/3499-1/\$20.00

DOI: $10.1200 / J C O .2015 .66 .0787$

\title{
Double-Blind, Placebo-Controlled, Randomized Phase III Trial Evaluating Pertuzumab Combined With Chemotherapy for Low Tumor Human Epidermal Growth Factor Receptor 3 mRNA-Expressing Platinum-Resistant Ovarian Cancer (PENELOPE)
}

Christian Kurzeder, Isabel Bover, Frederik Marmé, Joern Rau, Patricia Pautier, Nicoletta Colombo, Domenica Lorusso, Petronella Ottevanger, Maria Bjurberg, Christian Marth, Pilar Barretina-Ginesta, Ignace Vergote, Anne Floquet, Josep M. del Campo, Sven Mahner, Lydie Bastière-Truchot, Nicolas Martin, Mikkel Z. Oestergaard, Astrid Kiermaier, Carmen Schade-Brittinger, Sandra Polleis, Andreas du Bois, and Antonio Gonzalez-Martin

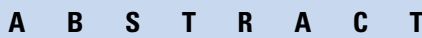

\section{Purpose}

The AGO-OVAR 2.29/ENGOT-ov14/PENELOPE prospectively randomized phase III trial evaluated the addition of pertuzumab to chemotherapy in patients with platinum-resistant ovarian carcinoma with low tumor human epidermal growth factor receptor 3 (HER3) mRNA expression. We report the results of the primary efficacy analysis.

\section{Patients and Methods}

Eligible patients had ovarian carcinoma that progressed during or within 6 months of completing four or more platinum cycles, centrally tested low tumor HER3 mRNA expression (concentration ratio $\leq 2.81$ by quantitative reverse transcriptase polymerase chain reaction on cobas $z 480$ [Roche Molecular Diagnostics, Pleasanton, CA]), and no more than two prior lines of chemotherapy. After investigators' selection of the chemotherapy backbone (single-agent topotecan, weekly paclitaxel, or gemcitabine), patients were randomly assigned to also receive either placebo or pertuzumab (840-mg loading dose followed by $420 \mathrm{mg}$ every 3 weeks). Stratification factors were selected chemotherapy, prior antiangiogenic therapy, and platinum-free interval. The primary end point was independent review committee-assessed progression-free survival (PFS). Additional end points included overall survival, investigator-assessed PFS, objective response rate, safety, patient-reported outcomes, and translational research.

\section{Results}

Overall, 156 patients were randomly assigned. Adding pertuzumab to chemotherapy did not significantly improve independent review committee-assessed PFS for the primary analysis (stratified hazard ratio, $0.74 ; 95 \% \mathrm{Cl}, 0.50$ to $1.11 ; P=.14$; median PFS, 4.3 months for pertuzumab plus chemotherapy $v$ 2.6 months for placebo plus chemotherapy). Sensitivity analyses and secondary efficacy end point results were consistent with the primary analysis. The effect on PFS favoring pertuzumab was more pronounced in the gemcitabine and paclitaxel cohorts. No new safety signals were seen.

\section{Conclusion}

Although the primary objective was not met, subgroup analyses showed trends in PFS favoring pertuzumab in the gemcitabine and paclitaxel cohorts, meriting further exploration of pertuzumab in ovarian cancer.

\section{J Clin Oncol 34. (C) 2016 by American Society of Clinical Oncology}

\section{INTRODUCTION}

The humanized monoclonal antibody pertuzumab is an established standard of care in human epidermal growth factor receptor (HER) 2-positive metastatic breast cancer, significantly improving progression-free survival (PFS) and overall survival
(OS) when combined with anti-HER2 therapy and chemotherapy. ${ }^{1-3}$ Pertuzumab inhibits HER2 binding with HER family members (HER1, HER3, and HER4). The HER2/HER3 heterodimer is the most potent in HER signaling, ${ }^{4}$ resulting in activation of various downstream signal transduction pathways (including $\mathrm{PI} 3 \mathrm{~K}$ ) and possible 
downregulation of HER3 mRNA. ${ }^{5,6}$ In ovarian cancer (OC) cell lines, pertuzumab reversed this downregulation. ${ }^{5,7}$

Two randomized phase II trials evaluated pertuzumab combined with chemotherapy in $\mathrm{OC}$, one in platinum-sensitive $\mathrm{OC}^{8}$ and one in platinum-resistant OC (PROC; TOC $3258 \mathrm{~g}$ ). ${ }^{5}$ Neither trial met its primary objective of significantly improving PFS in the overall population. However, in PROC, retrospective subgroup analyses demonstrated significantly improved PFS with pertuzumab in patients with low (below the study population median) tumor HER3 mRNA expression (PFS hazard ratio [HR], 0.32; 95\% CI, 0.17 to 0.59 ; median PFS, 5.3 months with pertuzumab $v 1.4$ months with placebo). ${ }^{5}$ Low HER3 mRNA expression also seemed to be associated with a particularly poor prognosis (median PFS with placebo plus gemcitabine: 1.4 months in patients with low HER3 mRNA expression $v 5.5$ months in those with high expression). A similar but less marked predictive and prognostic effect was seen in platinum-sensitive OC in the subgroup with shorter treatment-free intervals. ${ }^{8}$

These observations led to the design of the two-part Arbeitsgemeinschaft Gynäkologische Onkologie Ovarian Cancer Study Group (AGO-OVAR) 2.20/European Network for Gynecological Oncological Trial Groups (ENGOT) ov14/PENELOPE trial (Pertuzumab in Platinum-Resistant Low HER3 mRNA Epithelial Ovarian Cancer; ClinicalTrials.gov identifier: NCT01684878). Part 1 was a nonrandomized run-in phase to assess the safety of combining pertuzumab with either weekly paclitaxel or topotecan. Gemcitabine was not included because its tolerability with pertuzumab was previously established in the randomized TOC $3258 \mathrm{~g}$ trial. ${ }^{5}$ In part 1 of PENELOPE, no new safety signals were seen when pertuzumab was combined with either topotecan or weekly paclitaxel; both combinations were tolerable and feasible. ${ }^{9}$ Therefore, the trial proceeded to part 2, a prospectively randomized evaluation of chemotherapy with or without pertuzumab, reported here.

\section{PATIENTS AND METHODS}

\section{Study Design}

PENELOPE was a placebo-controlled double-blind multinational randomized phase III trial evaluating pertuzumab combined with the investigator's chosen chemotherapy. Before random assignment, investigators selected the backbone chemotherapy regimen for each patient (topotecan, weekly paclitaxel, or gemcitabine). Thereafter, patients were randomly assigned to receive either placebo or pertuzumab with the selected chemotherapy. Recruitment to each chemotherapy cohort was capped to ensure similar sample sizes. The stratification factors were as follows: selected chemotherapy, prior antiangiogenic therapy (yes $v$ no), and platinum-free interval (PFI; $<3 v 3$ to 6 months).

The primary end point was PFS as assessed by an independent review committee (IRC). PFS was defined as the interval between random assignment and disease progression according to Response Evaluation Criteria in Solid Tumors (RECIST; version 1.1) or malignant bowel obstruction (Appendix, online only) diagnosed in the setting of CA-125 progression, or death, whichever occurred first.

OS was a key secondary end point and part of a closed statistical testing procedure. Additional secondary end points included investigatorassessed PFS (including malignant bowel obstruction), objective response rate (ORR; best response according to RECIST 1.1 confirmed $\geq 4$ weeks after the first recorded response) in patients with measurable disease, clinical benefit rate (CBR; complete or partial response or stable disease maintained for $\geq 42$ days), safety, tolerability, and patient-reported outcomes.

\section{Patient Population}

Eligible patients had platinum-resistant or platinum-refractory epithelial ovarian, primary peritoneal, or fallopian tube carcinoma (progression during platinum therapy or within 6 months of completing four or more cycles of platinum-containing therapy) and low tumor HER3 mRNA expression. HER3 mRNA expression was assessed using quantitative reverse transcriptase polymerase chain reaction on cobas z480 (Roche Molecular Diagnostics, Pleasanton, CA). Low HER3 mRNA expression was defined as a concentration ratio $\leq 2.81$, corresponding to the 0.71 cutoff value on the LightCycler 2.0 (Roche Diagnostics) platform used in TOC3258g. ${ }^{5}$ The conversion formula transforming the cutoff to the new platform was determined in measurement equivalence studies.

Patients had to have at least one measurable or nonmeasurable lesion according to RECIST 1.1, an Eastern Cooperative Oncology Group performance status $\leq 2$, left ventricular ejection fraction $\geq$ $50 \%$, and be aged $\geq 18$ years old. Key exclusion criteria were as follows: more than two prior lines of chemotherapy, ongoing grade $\geq 2$ peripheral neuropathy at baseline (paclitaxel cohort only), inadequate organ function, or uncontrolled hypertension or clinically significant cardiovascular disease.

All patients provided written informed consent before undergoing any study-specific procedures. The trial conformed to the Declaration of Helsinki and Good Clinical Practice guidelines and was approved by the ethics committee of each participating site.

\section{Treatment}

Investigators selected one of the following intravenous chemotherapy options for each patient: topotecan $1.25 \mathrm{mg} / \mathrm{m}^{2}$ on days 1 to 5 every 3 weeks; paclitaxel $80 \mathrm{mg} / \mathrm{m}^{2}$ on days 1,8 , and 15 every 3 weeks; or gemcitabine $1,000 \mathrm{mg} / \mathrm{m}^{2}$ on days 1 and 8 every 3 weeks. Premedication was given according to local practice. Pertuzumab or placebo was administered intravenously every 3 weeks at a loading dose of $840 \mathrm{mg}$ on day 1 , followed by $420 \mathrm{mg}$ on day 1 of each subsequent cycle. Pertuzumab/ placebo and chemotherapy were continued until disease progression, unacceptable toxicity, consent withdrawal, or death, whichever occurred first.

\section{Study Assessments}

A formalin-fixed paraffin-embedded tumor block from each patient was submitted to a central laboratory for HER3 mRNA eligibility screening. Tumors were assessed by computed tomography or magnetic resonance imaging at baseline (within 28 days before the first dose), and then every 9 weeks until disease progression determined by the investigator using the same imaging method as at baseline. Additional tumor assessments were performed if disease progression was suspected between scheduled assessments. An IRC (blinded to treatment assignment) reviewed all radiographic and other tumor assessment data from all patients to assess responses. Adverse events (AEs) were monitored continuously and recorded from the first dose until the safety follow-up visit 28 days after treatment discontinuation. AEs were graded according to the National Cancer Institute Common Terminology Criteria for Adverse Events (version 4.0). Hematology and biochemistry tests, CA-125 levels, and coagulation tests were performed at baseline, before every cycle, and at the safety follow-up visit. Left ventricular ejection fraction was assessed within 28 days before the first dose and then every 9 weeks, ideally by echocardiogram or otherwise by multigated acquisition scan, using the same technique throughout the study. Standard 12-lead ECG assessments were performed at screening and then as clinically indicated. An Independent Data Monitoring Committee reviewed unblinded safety data regularly to monitor patient safety.

\section{Statistical Design and Analysis}

The planned part 2 sample size was 154 randomly assigned patients to ensure 140 evaluable patients (70 patients per treatment arm), assuming 
a $10 \%$ dropout rate. The primary PFS analysis was prespecified after 109 IRC-assessed PFS events. This provided $95 \%$ power to detect a PFS HR of 0.50 (median PFS increased from 1.4 to 2.8 months with pertuzumab added to chemotherapy) with a two-sided $\alpha=.05$ (logrank test). Assumptions were on the basis of results in a subset of patients with low (below median) tumor HER3 mRNA expression in TOC3258g. ${ }^{5}$

Because a slight delay between an investigator-recorded PFS event and prospective IRC assessment is unavoidable, it was foreseen that at the primary analysis, more than 109 IRC-assessed PFS events would have occurred. Consequently, one of the prespecified sensitivity analyses was on the basis of the first 109 IRC-assessed PFS events.

The trial had $80 \%$ power for OS (key secondary end point) using a closed-test procedure to adjust the significance level for multiple statistical testing. The final OS analysis is planned after 129 deaths. An interim OS analysis was prespecified at the time of the primary PFS analysis (boundaries presented in Appendix Table A1, online only).

PFS and OS were estimated using the Kaplan-Meier method. $P$ values for the stratified log-rank test (using randomization stratification factors) were calculated. In addition, HRs and associated 95\% CIs were calculated using the Cox regression model. The proportions of responders for ORR and CBR and the differences between treatments were calculated with associated 95\% Clopper-Pearson CIs.

Efficacy analyses were performed on the intent-to-treat population (all randomly assigned patients). Safety analyses were performed on the safety population (all patients who received at least one dose of study therapy).

\section{RESULTS}

\section{Patient Population}

HER3 mRNA eligibility criteria were met in 207 (68\%) of 306 patients with valid reverse transcriptase polymerase chain reaction results (Fig 1). Of these, 156 patients from 52 European centers were randomly assigned between October 2, 2013, and September 18, 2014. Three patients did not receive randomly assigned treatment; thus, the safety population included 153 patients (77 patients received pertuzumab plus chemotherapy; 76 patients received placebo plus chemotherapy). The gemcitabine cohort was the first to be fully recruited (March 2014), followed by paclitaxel (May 2014), and finally topotecan (September 2014).

Baseline characteristics were generally well balanced between treatment arms (Table 1). Comparison of baseline characteristics according to investigator-selected chemotherapy revealed some imbalances both between and within chemotherapy cohorts (Appendix Table A2, online only).

\section{Treatment Exposure}

At the data cutoff for the primary PFS analysis (January 30, 2015), the median duration of pertuzumab treatment was

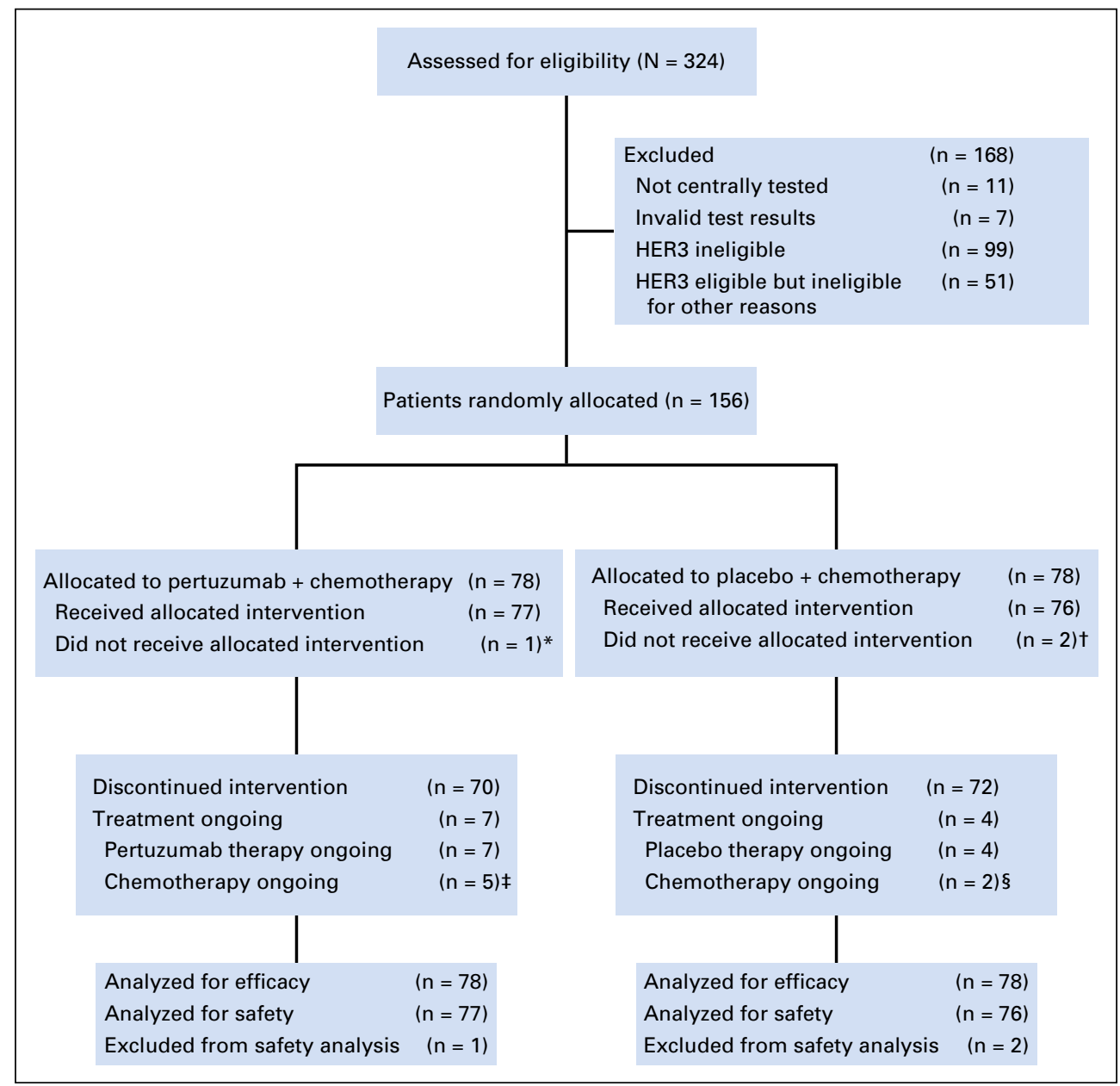

Fig 1. CONSORT diagram. HER3, human epidermal growth factor receptor $3 .\left(^{*}\right)$ Patient died before starting treatment. $(\dagger)$ Both patients withdrew consent before starting treatment. ( $\ddagger)$ Three patients on topotecan, one on paclitaxel, and one on gemcitabine. (§) One patient on topotecan and one on paclitaxel. 


\begin{tabular}{|c|c|c|c|c|}
\hline \multirow[b]{2}{*}{ Characteristic } & \multicolumn{2}{|c|}{$\begin{array}{l}\text { Pertuzumab + } \\
\text { Chemotherapy } \\
(\mathrm{n}=78)\end{array}$} & \multicolumn{2}{|c|}{$\begin{array}{c}\text { Placebo }+ \\
\text { Chemotherapy } \\
(\mathrm{n}=78)\end{array}$} \\
\hline & $\begin{array}{l}\text { No. of } \\
\text { Patients }\end{array}$ & $\%$ & $\begin{array}{l}\text { No. of } \\
\text { Patients }\end{array}$ & $\%$ \\
\hline \multicolumn{5}{|l|}{ Age, years } \\
\hline Median & \multicolumn{2}{|c|}{65} & \multicolumn{2}{|c|}{64} \\
\hline Range & \multicolumn{2}{|c|}{$32-79$} & \multicolumn{2}{|c|}{$26-80$} \\
\hline$>65$ & 38 & 48.7 & 34 & 43.6 \\
\hline$>75$ & 4 & 5.1 & 6 & 7.7 \\
\hline \multicolumn{5}{|l|}{ ECOG performance status } \\
\hline 0 & 41 & 52.6 & 38 & 48.7 \\
\hline 1 & 31 & 39.7 & 31 & 39.7 \\
\hline 2 & 5 & 6.4 & 9 & 11.5 \\
\hline 3 & 1 & 1.3 & 0 & 0 \\
\hline Prior second-line chemotherapy & $41^{*}$ & $52.6^{*}$ & 48 & 61.5 \\
\hline \multicolumn{5}{|l|}{ FIGO stage } \\
\hline I & 4 & 5.1 & 3 & 3.8 \\
\hline II & 4 & 5.1 & 5 & 6.4 \\
\hline III & 45 & 57.7 & 47 & 60.3 \\
\hline IV & 25 & 32.1 & 21 & 26.9 \\
\hline Missing & 0 & 0 & 2 & 2.6 \\
\hline \multicolumn{5}{|l|}{ Selected chemotherapy $†$} \\
\hline Topotecan & 25 & 32.1 & 24 & 30.8 \\
\hline Paclitaxel & 26 & 33.3 & 28 & 35.9 \\
\hline Gemcitabine & 27 & 34.6 & 26 & 33.3 \\
\hline \multicolumn{5}{|l|}{ Histology } \\
\hline Serous & 60 & 76.9 & 60 & 76.9 \\
\hline Endometrioid & 2 & 2.6 & 6 & 7.7 \\
\hline Clear cell & 6 & 7.7 & 4 & 5.1 \\
\hline Mucinous & 0 & 0 & 1 & 1.3 \\
\hline Adenocarcinoma (NOS) & 6 & 7.7 & 5 & 6.4 \\
\hline Other & 8 & 10.3 & 5 & 6.4 \\
\hline Mixed & 2 & 2.6 & 2 & 2.6 \\
\hline \multicolumn{5}{|l|}{ Origin of cancer } \\
\hline Ovary & 70 & 89.7 & 70 & 89.7 \\
\hline Fallopian tube & 6 & 7.7 & 3 & 3.8 \\
\hline Primary peritoneal & 5 & 6.4 & 11 & 14.1 \\
\hline Undetermined & 1 & 1.3 & 0 & 0 \\
\hline \multicolumn{5}{|l|}{ Grade } \\
\hline 1 & 6 & 7.7 & 2 & 2.6 \\
\hline 2 & 12 & 15.4 & 13 & 16.7 \\
\hline 3 & 54 & 69.2 & 52 & 66.7 \\
\hline Missing & 6 & 7.7 & 11 & 14.1 \\
\hline \multicolumn{5}{|l|}{ Outcome of initial surgery } \\
\hline $\begin{array}{l}\text { No macroscopic residual } \\
\text { disease }\end{array}$ & 42 & 53.8 & 37 & 47.4 \\
\hline Macroscopic residual disease & 27 & 34.6 & 29 & 37.2 \\
\hline Missing & 2 & 2.6 & 1 & 1.3 \\
\hline No surgery & 7 & 9.0 & 11 & 14.1 \\
\hline $\begin{array}{l}\text { Previous antiangiogenic } \\
\text { therapy }{ }^{\dagger}\end{array}$ & 27 & 34.6 & 30 & 38.5 \\
\hline Previous bevacizumab & 19 & 24.4 & 23 & 29.5 \\
\hline \multicolumn{5}{|l|}{ Platinum-free interval, monthst } \\
\hline$<3$ & 19 & 24.4 & 21 & 26.9 \\
\hline $3-6$ & 59 & 75.6 & 57 & 73.1 \\
\hline Measurable disease at baseline & 61 & 78.2 & 69 & 88.5 \\
\hline Ascites at baseline & 18 & 23.1 & 25 & 32.1 \\
\hline \multicolumn{5}{|c|}{$\begin{array}{l}\text { Abbreviations: ECOG, Eastern Cooperative Oncology Group; FIGO, In- } \\
\text { ternational Federation of Gynecology and Obstetrics; NOS, not otherwise } \\
\text { specified. } \\
\text { *Third line in two patients and fourth line in one patient. } \\
\text { tStratification factor (on the basis of interactive Web- and voice-response } \\
\text { system). }\end{array}$} \\
\hline
\end{tabular}

3.3 months (range, $<0.1$ to 14.5 months) in the pertuzumab plus chemotherapy arm, and the median duration of placebo treatment was 2.2 months (range, $<0.1$ to 10.6 months) in the placebo plus chemotherapy arm. In both treatment arms, the most common reason for discontinuing either study therapy was disease progression.

\section{Efficacy}

The median duration of follow-up was 10.3 months in the pertuzumab plus chemotherapy arm and 10.1 months in the placebo plus chemotherapy arm. IRC-assessed PFS events were reported in 66 patients $(85 \%)$ and 60 patients $(77 \%)$ receiving pertuzumab and placebo, respectively. Adding pertuzumab to chemotherapy did not statistically significantly improve IRC-assessed PFS (stratified HR, $0.74 ; 95 \%$ CI, 0.50 to 1.11 ; two-sided log-rank test, $P=.14$; Fig 2A). Median PFS was 4.3 months with pertuzumab plus chemotherapy compared with 2.6 months with placebo plus chemotherapy. Investigatorassessed PFS showed consistent results (Fig 2B). The concordance rate between IRC- and investigator-assessed PFS status was $95 \%$ in the pertuzumab plus chemotherapy arm and $88 \%$ in the placebo plus chemotherapy arm (Appendix Table A3, online only).

Sensitivity analyses supported the primary PFS analysis, with all showing the same direction of effect (Appendix Fig A1, online only). Notably, in the sensitivity analysis after 109 IRCassessed PFS events, the stratified HR was 0.61 (95\% CI, 0.39 to $0.94)$.

The interim OS analysis, which included $64 \%$ of the events required for the final OS analysis, showed no statistically significant difference between treatment arms (Fig 3). Response was evaluable in 130 patients (61 patients in pertuzumab plus chemotherapy arm and 69 patients in placebo plus chemotherapy arm). There was no significant difference in either IRCor investigator-assessed ORR between the treatment arms (Fig 4). IRC-assessed CBR was significantly higher with pertuzumab plus chemotherapy than placebo plus chemotherapy; however, a corresponding difference in investigator-assessed CBR was not observed (Fig 4).

Subgroup analyses of PFS suggested diverging treatment effects according to the chemotherapy partner (Fig 5). The direction of effect in the gemcitabine and paclitaxel cohorts favored pertuzumab, but this was not observed with topotecan. Nevertheless, the treatment-by-chemotherapy interaction $P$ value for PFS was $P=.16$. The direction of effect for IRC-assessed CBR favored pertuzumab in all three chemotherapy cohorts and was most pronounced with paclitaxel (Fig 4).

A more pronounced pertuzumab effect on PFS was observed in patients who had not received prior antiangiogenic therapy compared with those exposed to antiangiogenic agents (Fig 5), but $P=.14$ for the treatment-by-subgroup interaction. For PFI, there seemed to be a differential effect on treatment (interaction $P=.02$ ), with a PFS benefit from pertuzumab in patients with a PFI of 3 to 6 months (platinum-resistant cohort) but not in those with a PFI of $<3$ months (platinumrefractory cohort). 


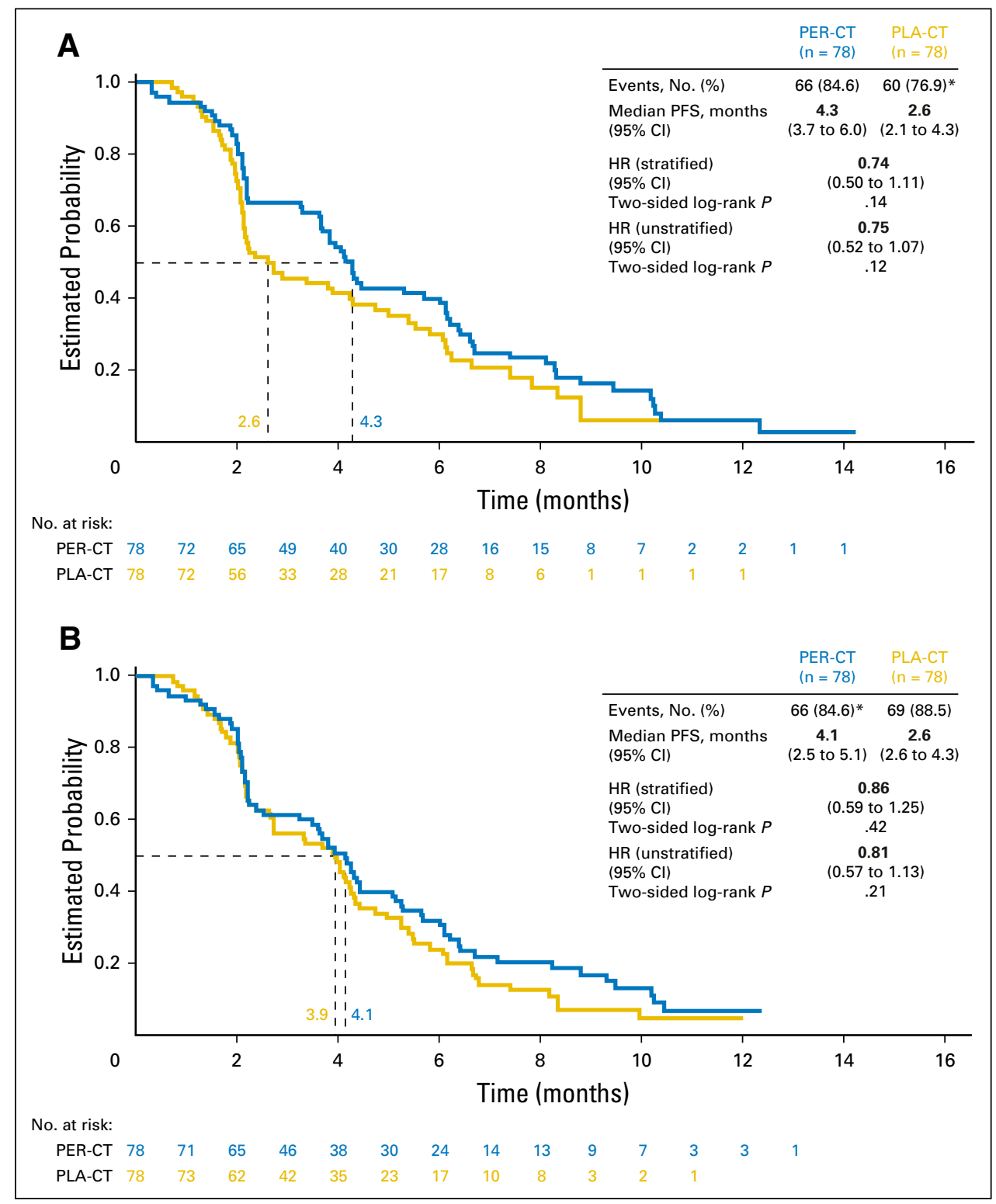

Fig 2. Progression-free survival (PFS), including malignant bowel obstruction, as assessed by (A) independent review committee (primary end point) and (B) investigators (secondary end point). HR, hazard ratio; PER-CT, pertuzumab plus chemotherapy; PLA-CT, placebo plus chemotherapy. $\left({ }^{*}\right)$ Malignant bowel obstruction criteria in one patient.

\section{Safety}

The most common AEs (all grades) with pertuzumab plus chemotherapy were diarrhea, fatigue/asthenia, nausea, neutropenia, and anemia, and the most common AEs with placebo plus chemotherapy were fatigue/asthenia, nausea, and anemia (Table 2). Grade $\geq 3$ AEs were slightly less frequent with pertuzumab plus chemotherapy $(69 \%)$ than placebo plus chemotherapy $(75 \%)$. Compared with placebo plus chemotherapy, pertuzumab-containing therapy was associated with an increased incidence of diarrhea (all grades and grade $\geq 3$ ) and grade $\geq 3$ neutropenia and slightly more grade $\geq 3$ nausea and vomiting, but less frequent constipation, grade $\geq 3$ intestinal obstruction, and grade $\geq 3$ fatigue/asthenia. AEs resulted in death in six patients $(8 \%)$ receiving pertuzumab plus chemotherapy (three as a result of OC, two unexplained deaths, and one as a result of general physical health deterioration) and 10 patients (13\%) receiving placebo plus chemotherapy (two as a result of intestinal obstruction and one each as a result of cerebral ischemia, hydrocephalus, acute myocardial infarction, encephalitis, pleural effusion, general physical health deterioration, performance status decreased, and OC). Pertuzumab/placebo was discontinued because of AEs in six patients (8\%) receiving pertuzumab plus chemotherapy and 14 patients (18\%) receiving placebo plus chemotherapy. Subgroup analyses of safety by chemotherapy cohort were generally consistent with the recognized safety profiles of the backbone chemotherapy (Appendix Table A4, online only).

\section{Biomarkers}

To explore potential differential benefit according to HER3 mRNA expression further, we conducted subgroup analyses applying HER3 mRNA cutoffs at the median and quartiles. Within 


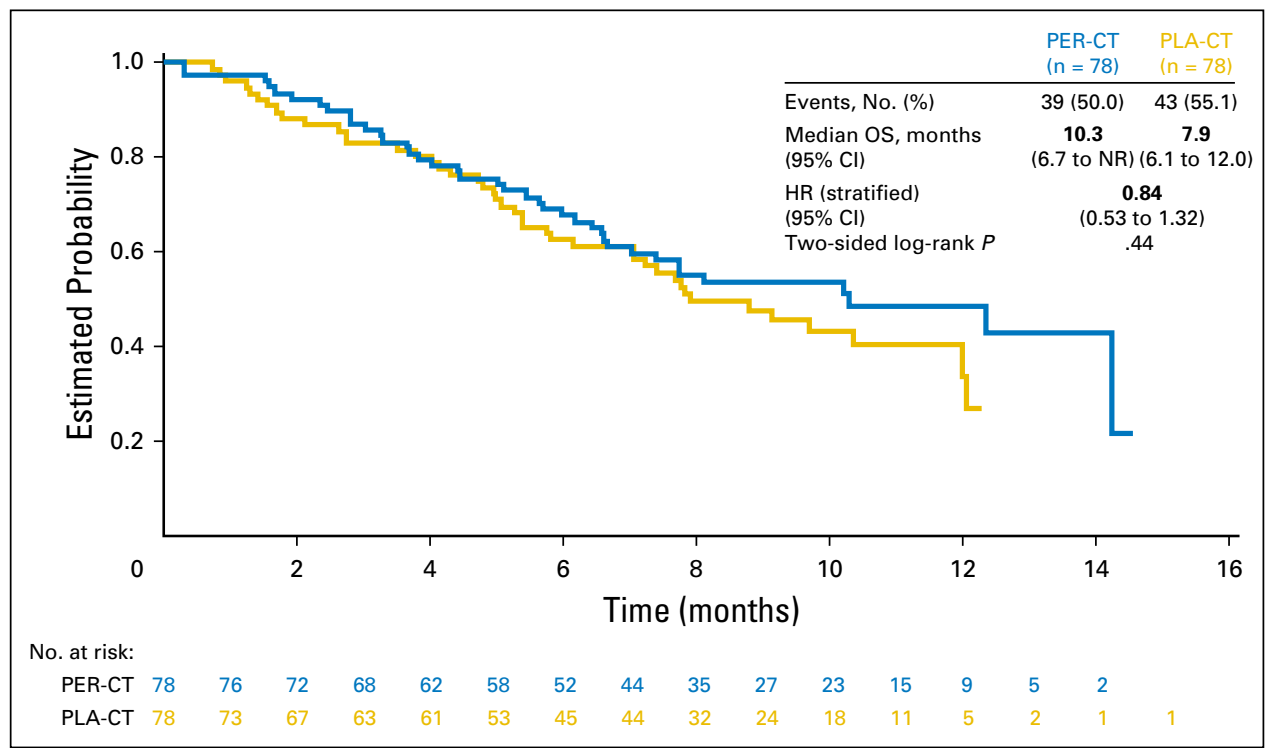

Fig 3. Interim overall survival (OS; key secondary end point). HR, hazard ratio; NR, not reached; PER-CT, pertuzumab plus chemotherapy; PLA-CT, placebo plus chemotherapy.

the preselected low tumor HER3 mRNA-expressing population treated in this study, the PFS HR was 0.79 (95\% CI, 0.48 to 1.33 ) in patients with HER3 mRNA expression less than the median cutoff value and 0.68 (95\% CI, 0.42 to 1.12$)$ in patients with HER3 mRNA expression greater than the median cutoff value (interaction $P=.68)$. In the control arm, median PFS durations were 2.7 and 2.6 months for low and high HER3 mRNA subgroups, respectively. Quartile analyses revealed no further consistent

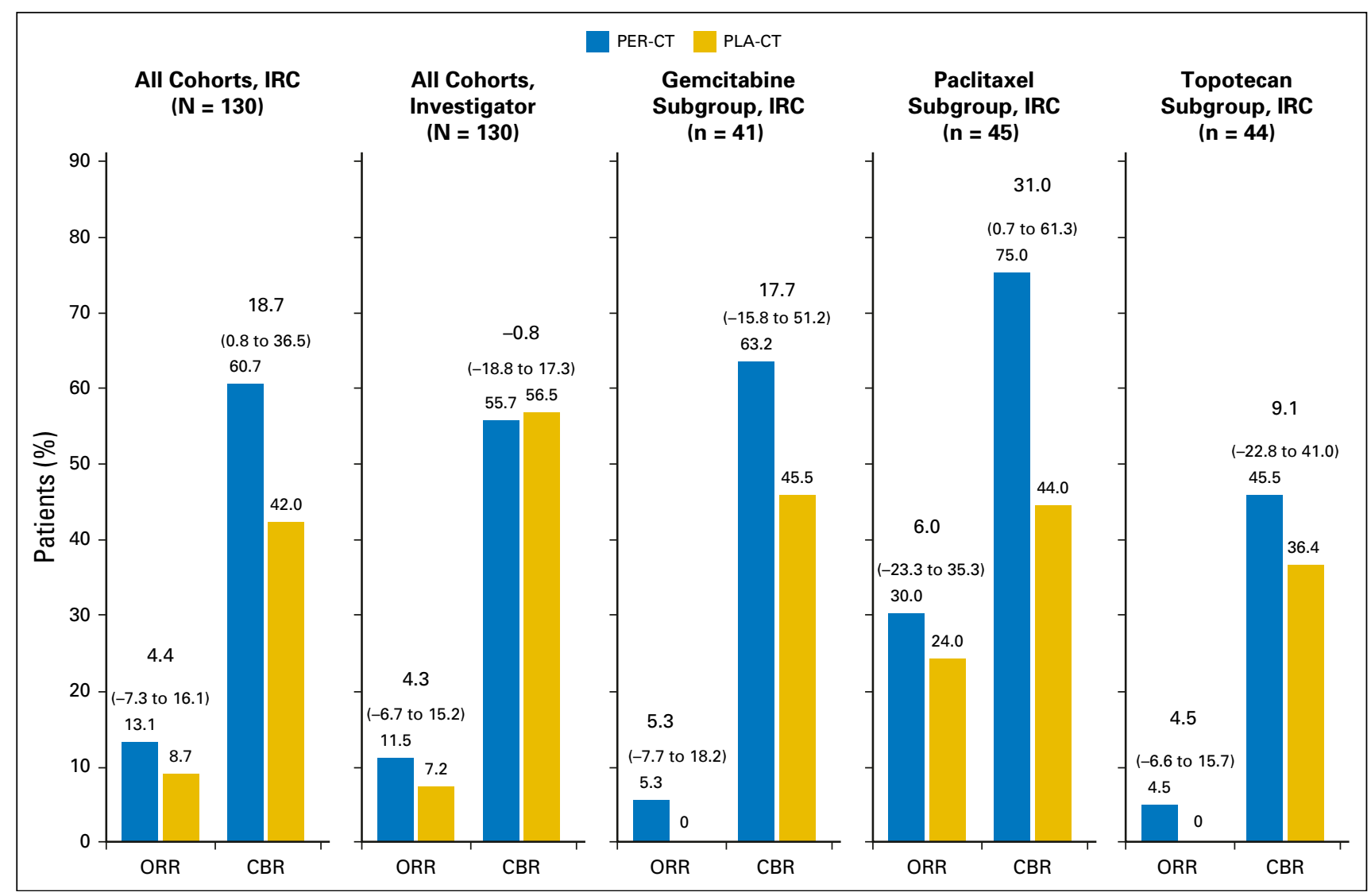

Fig 4. Objective response rate (ORR) and clinical benefit rate (CBR) in patients with measurable disease. Numbers above bars show difference between treatment arms. Numbers in parentheses show approximate $95 \% \mathrm{Cls}$ for the difference between the two rates using Hauck-Anderson method. IRC, independent review committee; PER$\mathrm{CT}$, pertuzumab plus chemotherapy; PLA-CT, placebo plus chemotherapy. 


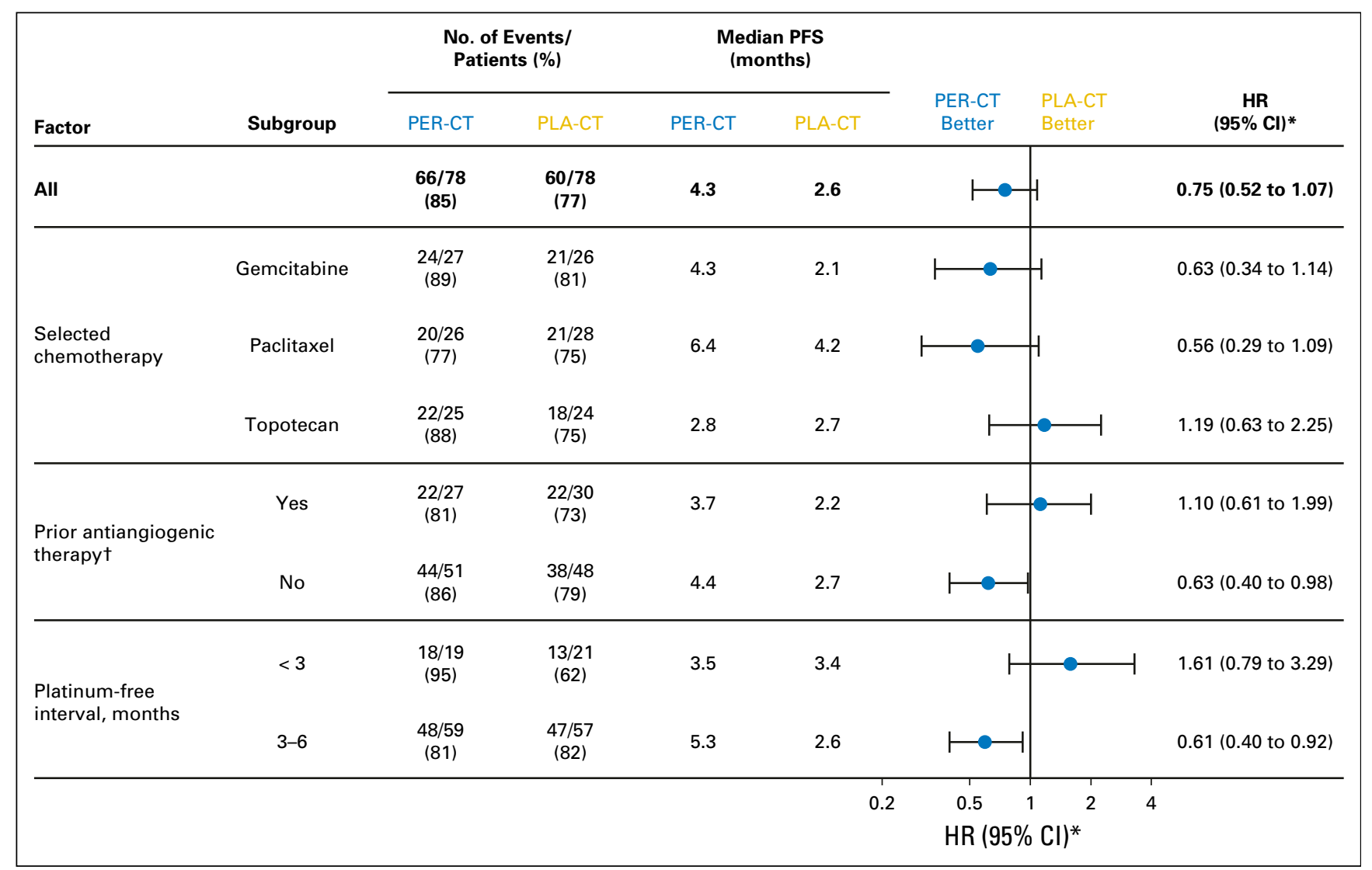

Fig 5. Subgroup analyses of independent review committee-assessed progression-free survival (PFS; including malignant bowel obstruction) according to stratification factors (according to interactive Web- and voice-response system). HR, hazard ratio; PER-CT, pertuzumab plus chemotherapy; PLA-CT, placebo plus chemotherapy. ${ }^{*}$ ) Unstratified analysis. (†) Patients who had participated in a blinded trial of an antiangiogenic agent were enrolled onto the same stratum as those who were known to have received previous antiangiogenic therapy.

differential benefit according to HER3 mRNA expression (Appendix Fig A2, online only).

\section{DISCUSSION}

AGO-OVAR 2.20 (PENELOPE) is one of the first trials in PROC in which the study cohort was selected by a biomarker identified in exploratory analyses of prior phase II studies. Combining pertuzumab with chemotherapy in these patients did not statistically significantly improve IRC-assessed PFS (primary end point; HR, $0.74 ; 95 \%$ CI, 0.50 to $1.11 ; P=.14$ ), although there was a numerical trend favoring the pertuzumab arm. This may be because the thresholds were overambitious on the basis of overoptimistic exploratory analyses defining the biomarker cutoff and suggesting a strong predictive effect of the biomarker for efficacy. On the basis of these assumptions, the sample size calculations led to a rather small phase III population heavily dependent on exactly repeating the effect observed in the exploratory model. Nevertheless, results for secondary end points (ORR, CBR, investigator-assessed PFS, and interim OS) were consistent with the primary analysis, as were sensitivity analyses.

Although neither IRC-assessed nor investigator-assessed PFS comparisons reached statistical significance, the effect of pertuzumab seemed larger in the former analysis. There was some discordance between IRC and investigator assessment of PFS, with greater disparity observed in the placebo plus chemotherapy arm than the pertuzumab plus chemotherapy arm. This contrasts with previous reports comparing IRC- and investigator-assessed PFS in phase III trials in OC. ${ }^{10-13}$

Another interesting observation is the suggested diverging effects according to chemotherapy partner, with PFS trends favoring pertuzumab in the gemcitabine and paclitaxel cohorts, but not the topotecan cohort. There is no clear biologic explanation for a more pronounced effect of pertuzumab with gemcitabine and paclitaxel than with topotecan. Importantly, the trial was not designed to assess efficacy in the individual chemotherapy cohorts or to compare efficacy between chemotherapy regimens. Chemotherapy selection was at the discretion of the investigators and was, therefore, likely influenced by patient and disease characteristics and prior treatment, which showed some imbalances both within and between chemotherapy cohorts. The apparent lack of effect of combining pertuzumab with topotecan should be treated with some caution given the small sample size and the exploratory nature of this subgroup analysis (although chemotherapy choice was a stratification factor). However, it does perhaps help to explain the lack of effect in the overall population and raises the question of whether pertuzumab merits further evaluation with paclitaxel or gemcitabine in selected patient populations. 


\begin{tabular}{|c|c|c|c|c|}
\hline \multirow[b]{2}{*}{ Adverse Event* } & \multicolumn{2}{|c|}{$\begin{array}{l}\text { Pertuzumab + } \\
\text { Chemotherapy } \\
(\mathrm{n}=77)\end{array}$} & \multicolumn{2}{|c|}{$\begin{array}{c}\text { Placebo + } \\
\text { Chemotherapy } \\
(\mathrm{n}=76)\end{array}$} \\
\hline & $\begin{array}{c}\text { No. of } \\
\text { Patients }\end{array}$ & $\%$ & $\begin{array}{c}\text { No. of } \\
\text { Patients }\end{array}$ & $\%$ \\
\hline Diarrhea & 52 & 67.5 & 23 & 30.3 \\
\hline Grade $\geq 3$ & 11 & 14.3 & 1 & 1.3 \\
\hline Fatigue/asthenia & 51 & 66.2 & 46 & 60.5 \\
\hline Grade $\geq 3$ & 6 & 7.8 & 9 & 11.8 \\
\hline Nausea & 32 & 41.6 & 33 & 43.4 \\
\hline Grade $\geq 3$ & 4 & 5.2 & 1 & 1.3 \\
\hline $\begin{array}{l}\text { Neutropenia/neutrophil count } \\
\text { decreased }\end{array}$ & 29 & 37.7 & 23 & 30.3 \\
\hline Grade $\geq 3$ & 24 & 31.2 & 16 & 21.1 \\
\hline Anemia & 29 & 37.7 & 30 & 39.5 \\
\hline Grade $\geq 3$ & 6 & 7.8 & 5 & 6.6 \\
\hline Vomiting & 21 & 27.3 & 21 & 27.6 \\
\hline Grade $\geq 3$ & 4 & 5.2 & 2 & 2.6 \\
\hline Abdominal pain & 17 & 22.1 & 22 & 28.9 \\
\hline Grade $\geq 3$ & 2 & 2.6 & 2 & 2.6 \\
\hline Alopecia & 15 & 19.5 & 21 & 27.6 \\
\hline Grade $\geq 3$ & 1 & 1.3 & 1 & 1.3 \\
\hline Decreased appetite & 13 & 16.9 & 17 & 22.4 \\
\hline Grade $\geq 3$ & 0 & 0 & 0 & 0 \\
\hline Constipation & 12 & 15.6 & 21 & 27.6 \\
\hline Grade $\geq 3$ & 0 & 0 & 1 & 1.3 \\
\hline LeukopeniaMBC count decreased & 9 & 11.7 & 14 & 18.4 \\
\hline Grade $\geq 3$ & 5 & 6.5 & 7 & 9.2 \\
\hline Hypokalemia & 9 & 11.7 & 5 & 6.6 \\
\hline Grade $\geq 3$ & 5 & 6.5 & 4 & 5.3 \\
\hline Thrombocytopenia & 4 & 5.2 & 6 & 7.9 \\
\hline Grade $\geq 3$ & 4 & 5.2 & 3 & 3.9 \\
\hline Hypertension & 4 & 5.2 & 5 & 6.6 \\
\hline Grade $\geq 3$ & 4 & 5.2 & 3 & 3.9 \\
\hline GGT increased & 3 & 3.9 & 6 & 7.9 \\
\hline Grade $\geq 3$ & 2 & 2.6 & 4 & 5.3 \\
\hline Intestinal obstruction & 2 & 2.6 & 5 & 6.6 \\
\hline Grade $\geq 3$ & 1 & 1.3 & 5 & 6.6 \\
\hline Febrile neutropenia & 2 & 2.6 & 4 & 5.3 \\
\hline Grade $\geq 3$ & 2 & 2.6 & 4 & 5.3 \\
\hline $\begin{array}{l}\text { NOTE. All grades in } \geq 20 \% \text { or grad } \\
\text { group. } \\
\text { Abbreviation: GGT, } \gamma \text {-glutamyl tran } \\
\text { * Medical Dictionary for Regulaton }\end{array}$ & $\begin{array}{l}n \geq 5 \\
\text { e. } \\
\text { ities }\end{array}$ & 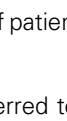 & eithe & nent \\
\hline
\end{tabular}

A significant PFS improvement with pertuzumab was observed in patients with a PFI of 3 to 6 months but not in patients with a PFI of $<3$ months. Although the interaction $P$ value indicated a significant impact of PFI on treatment effect, the small sample sizes must be considered before drawing conclusions from this observation. Nevertheless, it is interesting that imbalances between chemotherapy cohorts with respect to PFI favored pertuzumab in the gemcitabine cohort and favored placebo in the topotecan cohort.

When the PENELOPE trial was designed, pegylated liposomal doxorubicin could not be included as one of the three chemotherapy options because of ongoing supply issues. Therefore, topotecan, which is widely used in some countries, was chosen as an alternative. More recently, perceptions regarding the efficacy of topotecan have been challenged by exploratory analyses of the Avastin Use in Platinum-Resistant Epithelial Ovarian Cancer (AURELIA) trial, ${ }^{14}$ which evaluated the addition of bevacizumab to chemotherapy for PROC. In AURELIA, as in PENELOPE, chemotherapy choice was at the investigator's discretion, and comparisons of nonrandomized chemotherapy cohorts have obvious limitations. Nevertheless, it has been suggested that topotecan may be a suboptimal chemotherapy option in PROC. ${ }^{15}$ In both PENELOPE and AURELIA, topotecan alone demonstrated disappointing PFS and especially ORR. However, in contrast to PENELOPE, both PFS and ORR were significantly improved by adding bevacizumab to topotecan in AURELIA (PFS: HR, 0.32; 95\% CI, 0.21 to 0.49 ; ORR: $0 \%$ with topotecan alone $v 17 \%$ with topotecan plus bevacizumab). The final OS analysis of our trial (planned after 129 deaths) may provide greater insight into differences between chemotherapy cohorts.

In subgroup analyses of the TOC $3258 \mathrm{~g}$ trial according to HER3 mRNA expression quartile, patients with the lowest tumor HER3 mRNA expression gained greatest benefit from pertuzumab, with a linear relationship between magnitude of treatment effect and HER3 mRNA expression level. ${ }^{16}$ Quartile analyses of the present trial according to HER3 mRNA expression did not confirm the linear trend observed in TOC $3258 \mathrm{~g}$. Results were inconsistent, with the greatest pertuzumab effect seen in patients in the lowest and highest quartiles. However, PENELOPE was not designed either to test HER3 mRNA as a predictive biomarker or to validate the cutoff value defining low HER3 mRNA expression.

Pertuzumab seemed to be well tolerated with all chemotherapy partners, and there were no new safety signals. Diarrhea was more common with pertuzumab-containing therapy, consistent with previous experience in breast cancer and OC. Grade $\geq$ 3 neutropenia was also more common, as in the TOC $3258 \mathrm{~g}$ trial, ${ }^{5}$ but otherwise, there was little evidence of additive toxicity with pertuzumab-containing combination therapy.

In the two chemotherapy cohorts showing the most promising effect, HR point estimates were 0.63 (gemcitabine) and 0.56 (paclitaxel), making the ambitious target HR of 0.50 for this patient population even more debatable. These findings should be considered when designing future trials in this patient population.

In conclusion, although PENELOPE did not meet its primary objective, the results provide insight into the biology, prognosis, and management of PROC. These findings merit further exploration of pertuzumab with carefully selected chemotherapy partners in OC.

\section{AUTHORS' DISCLOSURES OF POTENTIAL CONFLICTS OF INTEREST}

Disclosures provided by the authors are available with this article at www.jco.org.

\section{AUTHOR CONTRIBUTIONS}

Conception and design: Christian Kurzeder, Joern Rau, Ignace Vergote, Lydie Bastière-Truchot, Mikkel Z. Oestergaard, Astrid Kiermaier, Carmen Schade-Brittinger, Sandra Polleis, Andreas du Bois

Administrative support: Sandra Polleis

Provision of study materials or patients: Christian Kurzeder, Frederik Marmé, Nicoletta Colombo, Domenica Lorusso, Petronella Ottevanger, 
Maria Bjurberg, Pilar Barretina-Ginesta, Ignace Vergote, Sven Mahner, Andreas du Bois

Collection and assembly of data: Christian Kurzeder, Isabel Bover, Frederik Marmé, Patricia Pautier, Nicoletta Colombo, Domenica Lorusso, Petronella Ottevanger, Pilar Barretina-Ginesta, Ignace Vergote, Josep M. del Campo, Sven Mahner, Lydie Bastière-Truchot, Mikkel Z. Oestergaard, Astrid Kiermaier, Andreas du Bois
Data analysis and interpretation: Christian Kurzeder, Joern Rau, Nicoletta Colombo, Domenica Lorusso, Maria Bjurberg, Christian Marth, Ignace Vergote, Anne Floquet, Sven Mahner, Lydie Bastière-Truchot, Nicolas Martin, Mikkel Z. Oestergaard, Astrid Kiermaier, Carmen SchadeBrittinger, Sandra Polleis, Andreas du Bois, Antonio Gonzalez-Martin Manuscript writing: All authors

Final approval of manuscript: All authors

\section{REFERENCES}

1. Baselga J, Cortés J, Kim SB, et al: Pertuzumab plus trastuzumab plus docetaxel for metastatic breast cancer. N Engl J Med 366:109-119, 2012

2. Swain SM, Baselga J, Kim SB, et al: Pertuzumab, trastuzumab, and docetaxel in HER2-positive metastatic breast cancer. N Engl J Med 372:724-734, 2015

3. Swain SM, Kim SB, Cortés J, et al: Pertuzumab, trastuzumab, and docetaxel for HER2-positive metastatic breast cancer (CLEOPATRA study): Overall survival results from a randomised, doubleblind, placebo-controlled, phase 3 study. Lancet Oncol 14:461-471, 2013

4. Bezler M, Hengstler JG, Ullrich A: Inhibition of doxorubicin-induced HER3-PI3K-AKT signalling enhances apoptosis of ovarian cancer cells. Mol Oncol 6:516-529, 2012

5. Makhija S, Amler LC, Glenn D, et al: Clinical activity of gemcitabine plus pertuzumab in platinumresistant ovarian cancer, fallopian tube cancer, or primary peritoneal cancer. J Clin Oncol 28:1215-1223, 2010

6. Chakrabarty A, Sánchez V, Kuba MG, et al: Feedback upregulation of HER3 (ErbB3) expression and activity attenuates antitumor effect of PI3K inhibitors. Proc Natl Acad Sci USA 109:2718-2723, 2012

7. Nagumo $Y$, Faratian $D$, Mullen $P$, et al: Modulation of HER3 is a marker of dynamic cell signaling in ovarian cancer: Implications for pertuzumab sensitivity. Mol Cancer Res 7:1563-1571, 2009

8. Kaye SB, Poole CJ, Dańska-Bidzińska A, et al: A randomized phase II study evaluating the combination of carboplatin-based chemotherapy with pertuzumab versus carboplatin-based therapy alone in patients with relapsed, platinum-sensitive ovarian cancer. Ann Oncol 24:145-152, 2013

9. Gonzalez-Martin A, Pautier P, Mahner S, et al: Pertuzumab plus chemotherapy for platinumresistant ovarian cancer: Safety run-in results of the PENELOPE trial. Int J Gynecol Cancer (in press)

10. Aghajanian C, Goff $B$, Nycum LR, et al: Independent radiologic review: Bevacizumab in combination with gemcitabine and carboplatin in recurrent ovarian cancer. Gynecol Oncol 133:105-110, 2014

11. Burger RA, Brady MF, Rhee J, et al: Independent radiologic review of the Gynecologic Oncology Group Study 0218, a phase III trial of bevacizumab in the primary treatment of advanced epithelial ovarian, primary peritoneal, or fallopian tube cancer. Gynecol Oncol 131: 21-26, 2013

12. Husain $A$, Wang $Y V$, Frederiksen $R$, et al: Independent radiologic review of AURELIA, a phase 3 trial of bevacizumab (BV) plus chemotherapy (CT) for platinum (PT)-resistant recurrent ovarian cancer (OC). J Clin Oncol 32:15S, 2014 (suppl; abstr 5540)

13. Floquet $A$, Vergote I, Colombo $N$, et al: Progression-free survival by local investigator versus independent central review: Comparative analysis of the AGO-OVAR16 Trial. Gynecol Oncol 136:37-42, 2015

14. Pujade-Lauraine E, Hilpert F, Weber B, et al: Bevacizumab combined with chemotherapy for platinum-resistant recurrent ovarian cancer: The AURELIA open-label randomized phase III trial. J Clin Oncol 32:1302-1308, 2014

15. Poveda AM, Selle F, Hilpert F, et al: Bevacizumab combined with weekly paclitaxel, pegylated liposomal doxorubicin, or topotecan in platinum-resistant recurrent ovarian cancer: Analysis by chemotherapy cohort of the randomized phase III AURELIA trial. J Clin Oncol 33:3836-3838, 2015

16. Amler LC: HER3 mRNA as a predictive biomarker in anticancer therapy. Expert Opin Biol Ther 10:1343-1355, 2010

\section{Affiliations}

Christian Kurzeder and Andreas du Bois, Arbeitsgemeinschaft Gynäkologische Onkologie (AGO) and Kliniken Essen Mitte, Essen; Frederik Marmé, AGO and University Hospital Heidelberg, Heidelberg; Joern Rau and Carmen Schade-Brittinger, Coordinating Center for Clinical Trials, Philipps-University of Marburg, Marburg; Sven Mahner, AGO and University Medical Center Hamburg-Eppendorf, Hamburg; Sandra Polleis, AGO Study Group, Wiesbaden, Germany; Isabel Bover, Grupo Español de Investigación en Cáncer de Ovario (GEICO) and Hospital Son Llàtzer, Palma de Mallorca; Pilar Barretina-Ginesta, GEICO and Catalan Institute of Oncology, Girona; Josep M. del Campo, GEICO and Vall d'Hebron University Hospital, Barcelona; Antonio Gonzalez-Martin, GEICO and MD Anderson Cancer Center Spain, Madrid, Spain; Patricia Pautier, Group d'Investigateurs Nationaux pour l'Etude des Cancers Ovariens (GINECO) and Institut Gustave Roussy, Villejuif; Anne Floquet, GINECO and Institut Bergonié, Bordeaux, France; Nicoletta Colombo, Mario Negri Gynecologic Oncology Group and University of Milan Bicocca-European Institute of Oncology; Domenica Lorusso, Multicenter Italian Trials in Ovarian Cancer and Fondazione Istituto di Ricovero e Cura a Carattere Scientifico, National Cancer Institute, Milan, Italy; Petronella Ottevanger, Dutch Gynecological Oncology Group and Radboud University Medical Center, Nijmegen, the Netherlands; Maria Bjurberg, Nordic Society of Gynecological Oncology and Department of Clinical Sciences, Skåne University Hospital, Lund University, Lund, Sweden; Christian Marth, AGO-Austria and Innsbruck Medical University, Innsbruck, Austria; Ignace Vergote, AGO and University Hospital Leuven, Leuven, Belgium; and Lydie Bastière-Truchot, Nicolas Martin, Mikkel Z. Oestergaard, and Astrid Kiermaier, F. Hoffmann-La Roche, Basel, Switzerland. 


\section{GLOSSARY TERMS}

Biomarker: a functional biochemical or molecular indicator of a biologic or disease process that has predictive, diagnostic, and/or prognostic utility.

CA-125 (cancer antigen 125): a protein produced by the fallopian tubes, the endometrium, and the lining of the abdominal cavity (peritoneum). CA-125 is a tumor marker present in higher than normal amounts in the blood and urine of patients with certain cancers. Typically, women with ovarian cancer have high levels of CA-125. Other conditions associated with elevated levels of CA-125 include endometriosis, pancreatitis, pregnancy, normal menstruation, and pelvic inflammatory disease. CA-125 levels may be used to help diagnose ovarian cancer and to determine whether these tumors are responding to therapy. The normal range for CA-125 is less than $35 \mathrm{U} / \mathrm{mL}$ and less than $20 \mathrm{U} / \mathrm{mL}$ for women who have been treated for ovarian cancer. Women with ovarian cancer may show values higher than $65 \mathrm{U} / \mathrm{mL}$.

hazard ratios: the ratio of the hazard rate in one group (for example, a group of treated patients) to the hazard rate in another group (for example, an untreated control group of patients). The hazard rate is the probability of a specified event, such as death or cancer recurrence, occurring during a short time interval. The hazard ratio, therefore, is a measure of the relative probability of an event occurring at any given point in time.

overall survival: the duration between random assignment and death.
Pertuzumab: a humanized monoclonal antibody that binds to HER2 at a site used by the receptor to form dimers with other receptors (the dimerization site) belonging to this family. Signaling via all HER2 dimers is, therefore, inhibited. Also referred to as Omnitarg. See HER2/ neu (human epidermal growth factor receptor 2) and ERBB2.

progression-free survival: time from random assignment until death or first documented relapse, categorized as either locoregional (primary site or regional nodes) failure or distant metastasis or death.

\section{RECIST (Response Evaluation Criteria in Solid}

Tumors): a model proposed by the Response Evaluation Criteria Group by which a combined assessment of all existing lesions, characterized by target lesions (to be measured) and nontarget lesions, is used to extrapolate an overall response to treatment.

stratification factor: a factor used to separate data into subgroups to determine whether that factor is significant; subgroup analysis is an analysis in which the intervention effect is evaluated in a defined subset of the participants in the trial or in complementary subsets, such as by sex or in age categories. Sample sizes in subgroup analyses are often small and subgroup analyses therefore usually lack statistical power. Comparison of subgroups should be done by test of interaction rather than by comparison of $P$ values. They are also subject to the multiple comparisons problem, which increases the probability of making a type I error (ie, attributing a difference to an intervention when chance is the more likely explanation). 


\section{AUTHORS' DISCLOSURES OF POTENTIAL CONFLICTS OF INTEREST}

Double-Blind, Placebo-Controlled, Randomized Phase III Trial Evaluating Pertuzumab Combined With Chemotherapy for Low Tumor Human Epidermal Growth Factor Receptor 3 mRNA-Expressing Platinum-Resistant Ovarian Cancer (PENELOPE)

The following represents disclosure information provided by authors of this manuscript. All relationships are considered compensated. Relationships are self-held unless noted. I = Immediate Family Member, Inst = My Institution. Relationships may not relate to the subject matter of this manuscript. For more information about ASCO's conflict of interest policy, please refer to www.asco.org/rwc or jco.ascopubs.org/site/ifc.

\section{Christian Kurzeder}

Honoraria: Roche, Amgen, AstraZeneca

Travel, Accommodations, Expenses: Roche, Amgen, PharmaMar

\section{Isabel Bover}

No relationship to disclose

\section{Frederik Marmé}

Honoraria: Roche, Amgen, Eisai, Novartis, PharmaMar, Celgene, Genomic Health

Consulting or Advisory Role: Amgen, Celgene, Novartis, Roche Travel, Accommodations, Expenses: Roche, Celgene, Novartis, Amgen, PharmaMar

\section{Joern Rau}

No relationship to disclose

\section{Patricia Pautier}

Consulting or Advisory Role: Roche, AstraZeneca, PharmaMar, GlaxoSmithKline

\section{Nicoletta Colombo}

Consulting or Advisory Role: Genentech, PharmaMar, Amgen, AstraZeneca, Clovis Oncology, Pfizer, MSD Oncology

\section{Domenica Lorusso}

Consulting or Advisory Role: Roche, PharmaMar, AstraZeneca Speakers' Bureau: Roche

Research Funding: PharmaMar (Inst)

Travel, Accommodations, Expenses: Roche, PharmaMar

\section{Petronella Ottevanger}

Consulting or Advisory Role: PharmaMar, Merck, Roche, AstraZeneca, Novartis (Inst)

Research Funding: PharmaMar (Inst)

Travel, Accommodations, Expenses: Novartis, AstraZeneca, Merck, PharmaMar

\section{Maria Bjurberg}

Research Funding: Roche (Inst), Boehringer Ingelheim (Inst), PROBI (Inst)

Christian Marth

No relationship to disclose

Pilar Barretina-Ginesta

Honoraria: AstraZeneca, Janssen, Roche

Consulting or Advisory Role: AstraZeneca, Roche

Travel, Accommodations, Expenses: Janssen, Roche

\section{Ignace Vergote}

Consulting or Advisory Role: Roche (Inst)

Speakers' Bureau: Roche

Research Funding: Roche (Inst)

Travel, Accommodations, Expenses: Roche

Anne Floquet

Travel, Accommodations, Expenses: Roche, PharmaMar, AstraZeneca

Josep M. del Campo

Consulting or Advisory Role: Merck, PharmaMar, Roche

\section{Sven Mahner}

Honoraria: Genentech, AstraZeneca, PharmaMar, Medac, Jenapharm, Janssen-Cilag, Teva, GlaxoSmithKline

Consulting or Advisory Role: Roche, AstraZeneca, Merck Sharp \& Dohme, Janssen-Cilag, Tesaro, Medac

Research Funding: Roche, AstraZeneca, Boehringer Ingelheim, GlaxoSmithKline, Janssen-Cilag, Medac, PharmaMar, Tesaro, Bayer

Lydie Bastière-Truchot

Employment: F. Hoffmann-La Roche

Nicolas Martin

Employment: F. Hoffmann-La Roche

Mikkel Z. Oestergaard

Employment: F. Hoffmann-La Roche

\section{Astrid Kiermaier}

Employment: F. Hoffmann-La Roche

Stock or Other Ownership: F. Hoffmann-La Roche

Patents, Royalties, Other Intellectual Property: Pending patent application: Identification of nonresponders to HER2 inhibitors \#30777EP (11192862.0) 30777US

Carmen Schade-Brittinger

No relationship to disclose

Sandra Polleis

No relationship to disclose

Andreas du Bois

Consulting or Advisory Role: AstraZeneca, PharmaMar, Genentech, Mundipharma, Pfizer

Antonio Gonzalez-Martin

Consulting or Advisory Role: Roche, PharmaMar, Amgen, AstraZeneca Speakers' Bureau: Roche, AstraZeneca, PharmaMar Travel, Accommodations, Expenses: Roche, PharmaMar 


\section{Acknowledgment}

We thank all the patients and their families who participated in this trial. Furthermore, we thank the following participating investigators and their supporters at the study sites in Spain, Germany, Belgium, France, Italy, the Netherlands, Norway, Sweden, Denmark, and Austria: A. Gonzalez-Martin, J.-M. del Campo, I. Bover, P. Barretina-Ginesta, B. Pardo Burdalo, J. Martinez, E. Ortega, Y. Garcia, N. Romero, A. Redondo, A. Poveda, A. Herrero, L. Vidal, M. J. Rubio, M. Romeo, C. Mendiola, J.-A. Arranz, A. Santaballa, and A. Gomez de Liano (Grupo Español de Investigación en Cáncer de Ovario); C. Kurzeder, F. Marmé, S. Mahner, F. Hilpert, U. Canzler, H.-J. Lueck, A. Zorr, E.-M. Grischke, M. Gropp-Meier, P. Cayir, B. Schmalfeldt, B. Rautenberg, W. Meier, A. Belau, B. Gerber, D. Rein, C. Jackisch, W. Janni, M. Heubner, and I. Vergote (Arbeitsgemeinschaft Gynaekologische Onkologie Study Group); P. Pautier, M. Fabbro, F. Selle, D. Berton-Rigaud, A. Floquet, B. You, L. Favier, F. Joly, B. Weber, and A.-C. Hardy-Bessard (Group d'Investigateurs Nationaux pour l'Étude des Cancers Ovariens); N. Colombo, A. Gadducci, G. Tognon, and A. DeCensi (Mario Negri Gynecologic Oncology Group); D. Lorusso, A. Savarese, and C. Pisano (Multicenter Italian Trials in Ovarian Cancer); P. Ottevanger, J. Kroep, G. Sonke, and A. Reyners (Dutch Gynecologic Oncology Group); G. Kristensen, M. Bjurberg, P. Rosenberg, and M.-R. Mirza (Nordic Society of Gynecological Oncology); and C. Marth (Arbeitsgemeinschaft Gynaekologische Onkologie Austria).

The PENELOPE Steering Committee also thanks the Independent Data Monitoring Committee for PENELOPE (M. Bookman [Chair], K. Winter, and D. Fink), the members of the translational research team at F. Hoffmann-La Roche (L. Amler, M. Sliwkowski, R. Deurloo, A. Kiermaier, and M. Oestergaard), L. Steiner (Roche Molecular Diagnostics), the patient-reported outcomes subcommittee (F. Hilpert, E. Greimel, and P. Ottevanger), the statisticians (J. Rau, C. Schade-Brittinger, B. Aminossadati [KKS], L. Mitchell [Roche], U. Freudensprung [former Roche employee], and J. Oyee [Covance]), and all involved staff at Covance responsible for data and safety management and medical monitoring. We also thank the central study offices of the study groups and all involved staff at F. Hoffmann-La Roche and at its affiliates in the countries listed earlier, as well as J. Kelly (Medi-Kelsey) for writing assistance (third-party writing assistance was supported by F. Hoffmann-La Roche, Basel, Switzerland).

\section{Appendix}

\section{Malignant Bowel Obstruction Criteria}

Assessment of abdominal symptoms indicative of malignant bowel obstruction. If cancer antigen (CA) -125 progression was diagnosed, the following abdominal symptoms indicative of malignant bowel obstruction (MBO) were assessed and documented in the electronic case report form (eCRF): abdominal pain, nausea, vomiting, abdominal distension, constipation, and diarrhea.

If one of these abdominal symptoms was new or had worsened by at least one grade (National Cancer Institute Common Terminology Criteria for Adverse Events), it was considered present. In this case, the complete set of diagnostic criteria for MBO (MBO criteria) were assessed and reported.

Assessment of $M B O$ criteria. If one or more of the abdominal symptoms indicative of $\mathrm{MBO}$ listed earlier was present and the increase in CA-125 fulfilled the criteria for CA-125 progression, nonmalignant causes of these symptoms were assessed and reported in the eCRF to reliably exclude nonmalignant causes of bowel obstruction.

First, there had to be no evidence of metabolic or electrolyte abnormalities that may lead to impaired intestinal motility. If metabolic abnormalities or electrolyte disturbances were detected that were considered to be causative of the abdominal symptoms of the patient, $\mathrm{MBO}$ could not be diagnosed according to the definition of this protocol.

Second, the investigator judged the abdominal symptom(s) as described earlier as not related to the investigational medicinal product (IMP). This could be the case if abdominal symptoms began after a phase of good tolerability of the IMP.

Third, the investigator judged the abdominal symptoms as not related to any concomitant medication (eg, constipation as a result of 5-hydroxytryptamine-3 receptor antagonists or hyperglycemia as a result of corticosteroids). This may not be the case if the abdominal symptom concerned is listed as an adverse event in the summary of product characteristics or package insert of the respective drug or if the abdominal symptoms started shortly after initiation of treatment with the respective drug or an elevation of dose.

If the investigator judged the abdominal symptom(s) described earlier as related to the IMP or any concomitant medication, MBO could not be diagnosed according to the definition of this protocol. In addition, the investigator had to assess that there was no evidence of any of the following: mechanical obstruction as a result of nonmalignant causes (eg, adhesions, hernia, volvulus); inflammatory causes (eg, diverticulitis, Crohn disease, ulcerous colitis, ischemic colitis, cystitis); or acute abdominal symptoms of nonmalignant etiology (eg, pancreatitis, cholecystitis, intestinal perforation, intestinal ischemia, intestinal pseudo-obstruction [Ogilvie syndrome]).

Prior computed tomography imaging was to be (re)assessed for evidence of these and other suspected causes. Further assessments may have been performed and documented in the eCRF to reliably exclude other suspected causes as clinically indicated. 
At a minimum, these assessments were to include the following laboratory parameters: glucose, sodium, potassium, calcium, magnesium, creatinine, AST, ALT, $\gamma$-glutamyl transferase, alkaline phosphatase, lipase, lactate dehydrogenase, total bilirubin and direct bilirubin (if total bilirubin is elevated), blood urea nitrogen, uric acid, total protein (or albumin only), C-reactive protein, and urine analysis (dipstick). The clinical and laboratory data were to be documented in the eCRF whenever MBO was suspected and were subjected to central independent review.

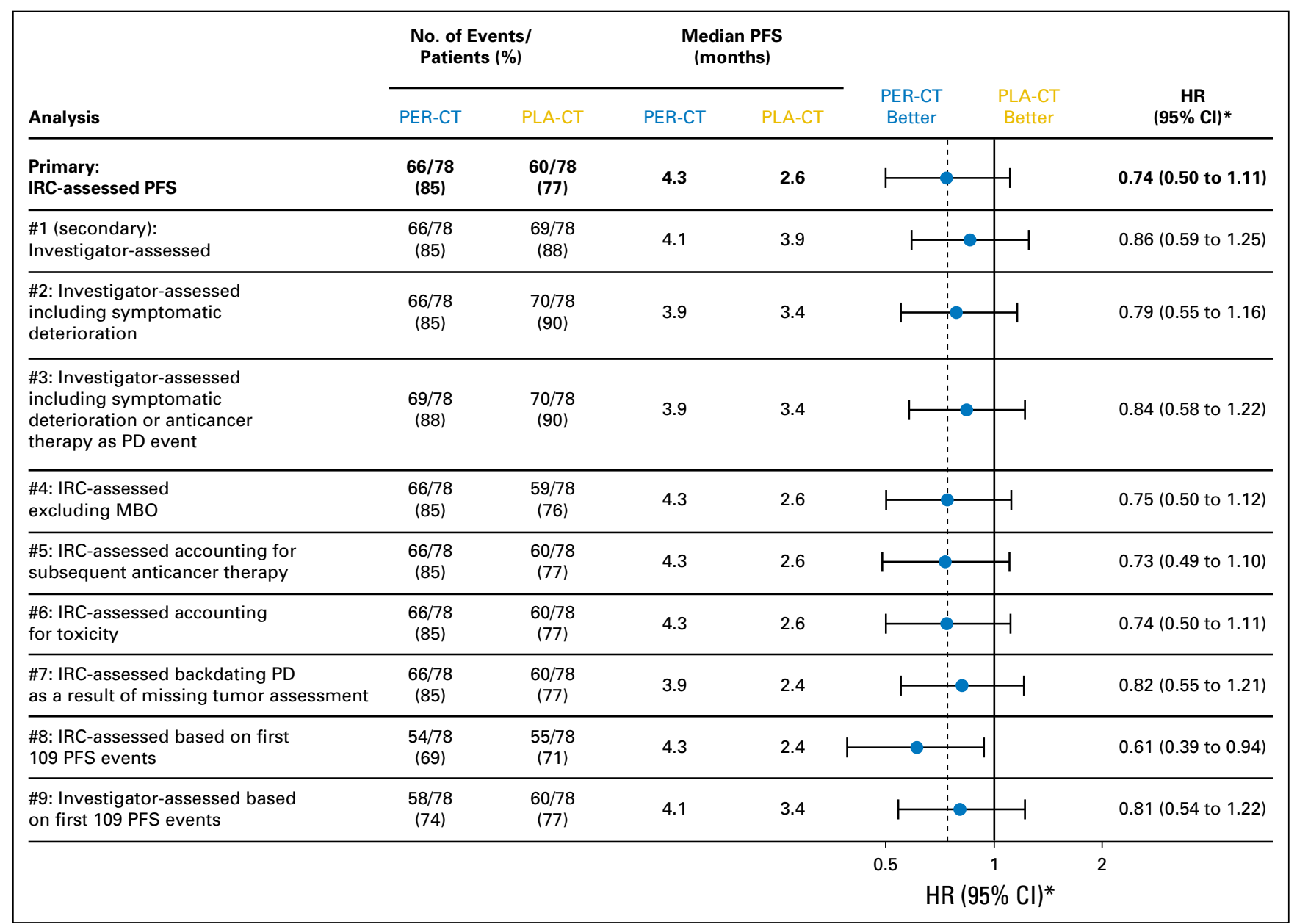

Fig A1. Summary of prespecified sensitivity analyses of progression-free survival (PFS). HR, hazard ratio; IRC, independent review committee; MBO, malignant bowel obstruction; PD, progressive disease; PER-CT, pertuzumab plus chemotherapy; PLA-CT, placebo plus chemotherapy. $\left({ }^{*}\right)$ Stratified analysis. 


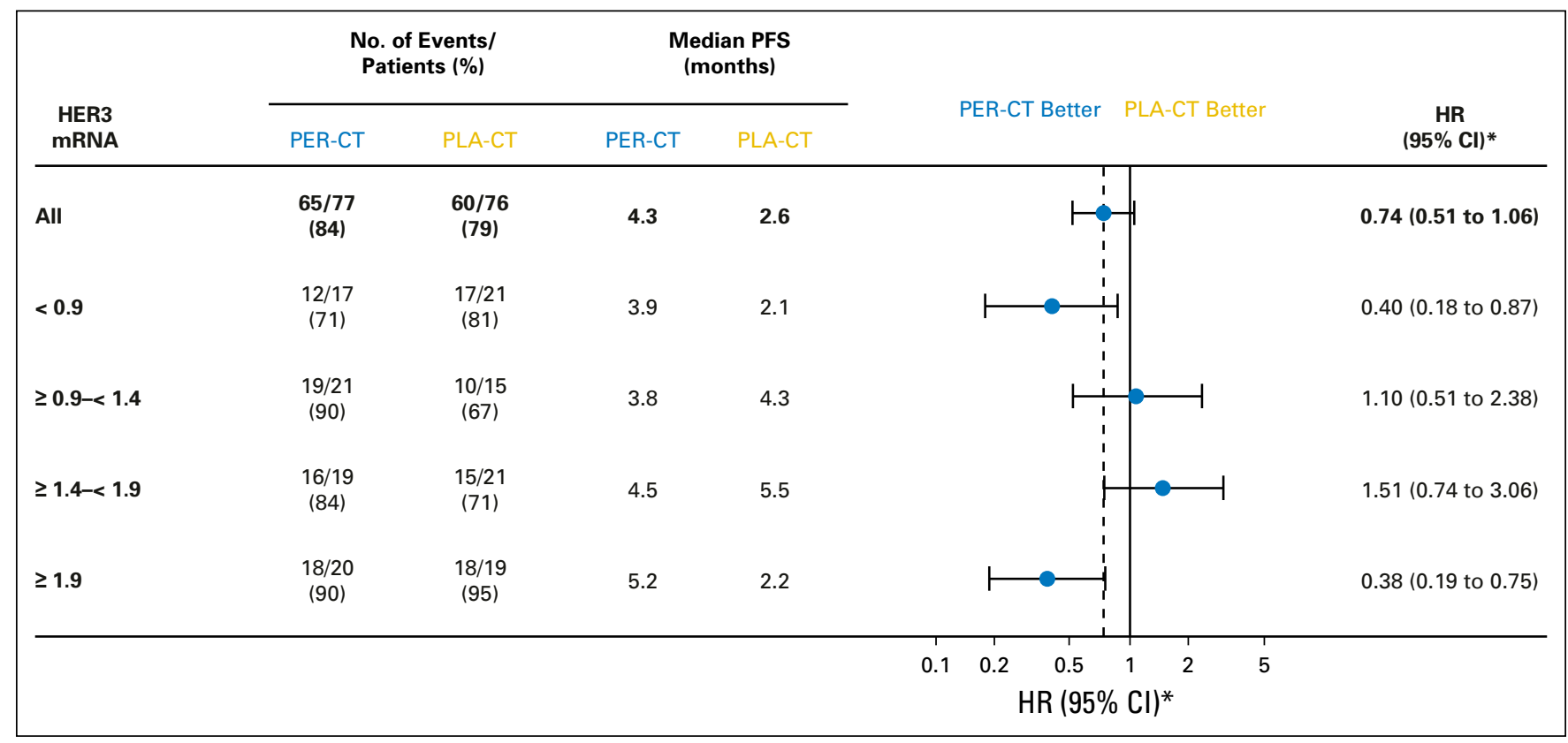

Fig A2. Independent review committee-assessed progression-free survival (PFS) according to human epidermal growth factor receptor 3 (HER3) mRNA quartile (unstratified analysis). HR, hazard ratio; PER-CT, pertuzumab plus chemotherapy; PLA-CT, placebo plus chemotherapy. $\left(^{*}\right.$ ) Unstratified analysis.

\begin{tabular}{|c|c|c|}
\hline \multicolumn{3}{|c|}{$\begin{array}{l}\text { Table A1. Summary of Planned OS Analyses and the Efficacy Stopping } \\
\text { Boundary }\end{array}$} \\
\hline OS Analysis & $\begin{array}{l}\text { No. of } \\
\text { Deaths }\end{array}$ & Efficacy Stopping Boundary \\
\hline $\begin{array}{l}\text { Interim analysis at } \\
\text { the time of the PFS } \\
\text { analysis }\end{array}$ & 81 & $\begin{array}{l}\text { Two-sided } P<.0094 \text { (corresponds } \\
\text { to an observed HR of } 0.5613 \text { ) }\end{array}$ \\
\hline Final analysis & 129 & $\begin{array}{l}\text { Two-sided } P<.0471 \text { (corresponds to } \\
\text { a HR of } 0.7049 \text { ) }\end{array}$ \\
\hline \multicolumn{3}{|c|}{$\begin{array}{l}\text { Abbreviations: HR, hazard ratio; OS, overall survival; PFS, progression-fre } \\
\text { survival. }\end{array}$} \\
\hline
\end{tabular}


Table A2. Baseline Characteristics (as recorded in the CRF) by Chemotherapy Cohort and Treatment Arm

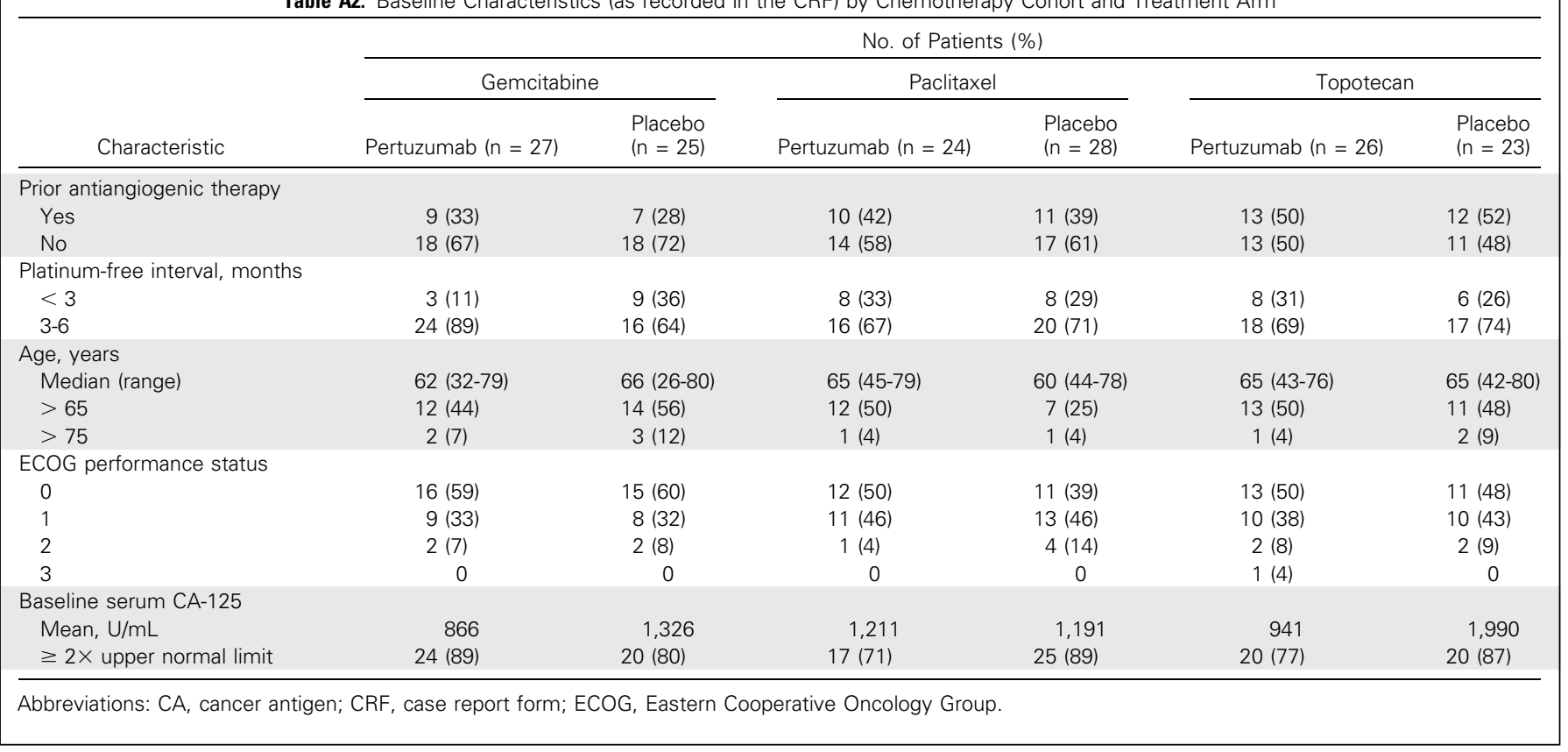

Table A3. Concordance Between Investigator-Assessed and IRC-Assessed RECIST PFS Status

\begin{tabular}{|c|c|c|c|c|c|c|}
\hline \multirow[b]{3}{*}{ RECIST PFS Status by IRC Assessment } & \multicolumn{6}{|c|}{ RECIST PFS Status by Investigator Assessment, No. (\%) } \\
\hline & \multicolumn{2}{|c|}{$\begin{array}{c}\text { Pertuzumab }+ \\
\text { Chemotherapy }(n=78)\end{array}$} & \multicolumn{2}{|c|}{$\begin{array}{c}\text { Placebo + Chemotherapy } \\
(\mathrm{n}=78)\end{array}$} & \multicolumn{2}{|c|}{ Total $(\mathrm{N}=156)$} \\
\hline & Yes & No & Yes & No & Yes & No \\
\hline Yes & $64(82)$ & $2(3)$ & $60(77)$ & 0 & $124(79)$ & $2(1)$ \\
\hline No & 2 (3) & $10(13)$ & $9(12)$ & $9(12)$ & $11(7)$ & $19(12)$ \\
\hline
\end{tabular}

Abbreviations: IRC, independent review committee; PFS, progression-free survival; RECIST, Response Evaluation Criteria in Solid Tumors.

\begin{tabular}{|c|c|c|c|c|c|c|}
\hline \multirow[b]{3}{*}{ Grade $\geq 3$ Adverse Event } & \multicolumn{6}{|c|}{ No. of Patients (\%) } \\
\hline & \multicolumn{2}{|c|}{ Gemcitabine } & \multicolumn{2}{|c|}{ Paclitaxel } & \multicolumn{2}{|c|}{ Topotecan } \\
\hline & $\begin{array}{l}\text { Pertuzumab } \\
\quad(n=27)\end{array}$ & $\begin{array}{l}\text { Placebo } \\
(\mathrm{n}=25)\end{array}$ & $\begin{array}{l}\text { Pertuzumab } \\
\qquad(\mathrm{n}=24)\end{array}$ & $\begin{array}{l}\text { Placebo } \\
(n=28)\end{array}$ & $\begin{array}{l}\text { Pertuzumab } \\
\quad(n=26)\end{array}$ & $\begin{array}{l}\text { Placebo } \\
(\mathrm{n}=23)\end{array}$ \\
\hline Any & $18(66.7)$ & $20(80.0)$ & $15(62.5)$ & $20(71.4)$ & $20(76.9)$ & 17 (73.9) \\
\hline $\begin{array}{l}\text { Neutropenia/neutrophil count } \\
\text { decreased }\end{array}$ & $10(37.0)$ & $4(16.0)$ & $5(20.8)$ & $4(14.3)$ & $9(34.6)$ & $8(34.8)$ \\
\hline Febrile neutropenia & $1(3.7)$ & 0 & 0 & 0 & $1(3.8)$ & $4(17.4)$ \\
\hline Leukopenia/WBC count decreased & 0 & 0 & 0 & $2(7.1)$ & $5(19.2)$ & $5(21.7)$ \\
\hline Anemia & $2(7.4)$ & $1(4.0)$ & 0 & $1(3.6)$ & $4(15.4)$ & $3(13.0)$ \\
\hline Thrombocytopenia & 0 & 0 & 0 & 0 & $4(15.4)$ & $3(13.0)$ \\
\hline Diarrhea & $3(11.1)$ & 0 & $5(20.8)$ & $1(3.6)$ & $3(11.5)$ & 0 \\
\hline Vomiting & 0 & 0 & $3(12.5)$ & $2(7.1)$ & $1(3.8)$ & 0 \\
\hline Asthenia/fatigue & $1(3.7)$ & $2(8.0)$ & $2(8.3)$ & $2(7.1)$ & $3(11.5)$ & $5(21.7)$ \\
\hline Peripheral neuropathy & 0 & 0 & $3(12.5)$ & $1(3.6)$ & 0 & 0 \\
\hline Hypertension & $1(3.7)$ & $3(12.0)$ & $1(4.2)$ & 0 & $2(7.7)$ & 0 \\
\hline General physical health deterioration & 0 & 0 & 0 & $1(3.6)$ & $3(11.5)$ & $1(4.3)$ \\
\hline Intestinal obstruction & $1(3.7)$ & $3(12.0)$ & 0 & $2(7.1)$ & 0 & 0 \\
\hline
\end{tabular}

